\title{
UWE-KARSTEN HEYE, Los Benjamin. Una familia alemana, Trotta, Madrid, 2020.
}

La editorial Trotta nos trae la última publicación -y primera editada en castellano- de Uwe-Karsten Heye: "Los Benjamin. Una familia alemana" (Die Benjamins. Eine deutsche Familie). Aunque con una larga carrera editorial en su Alemania natal, las principales referencias con que contábamos en España de Uwe-Karsten Heye eran por su faceta política. Históricamente vinculado al Partido Socialdemócrata de Alemania (SPD), entre 1974 y 1978 fue jefe de prensa del canciller Willy Brandt, entre 1990 y 1998 portavoz de Gerard Schröder cuando este gobernaba en Baja Sajonia, y, a partir de 1998, jefe de su oficina de prensa y portavoz del gobierno federal tras la llegada de Schröder a la cancillería. Sin embargo, es ahora cuando recibimos en España uno de sus libros más sugerentes, a través del cual realiza un recorrido por la historia alemana del siglo XX desde una perspectiva prosopográfica, siguiendo el camino marcado por la familia Benjamin. Esta no fue una familia más: se trata de la familia del filósofo Walter Benjamin, tronco principal de la obra a partir de la cual surgen diversas ramas en las que se entrecruzan tanto los parientes con una trayectoria pública relevante (su cuñada Hilde Benjamin) como los que se mantuvieron en la sombra de los segundos planos (su hermana Dora). Sin embargo, su diversa relevancia no conlleva un trato diferencial por parte del autor, pues lo que realmente le interesa son las vicisitudes que todos ellos vivieron a raíz de la turbulenta historia de Alemania durante el siglo XX.

La primera parte de la obra se centra en la historia de Walter Benjamin (18921940), su hermano Georg (1895-1942) y su hermana Dora (1901-1946). Tres hermanos procedentes de la alta burguesía judía cuya vida se vio truncada por la llegada de Hitler al poder: Walter se suicidó, Georg murió en el campo de concentración de Mauthausen y Dora pereció enferma en el exilio. La parte dedicada a los tres hermanos es sin duda la más sugestiva de la obra, entrelazando sus vidas y experiencias en dirección hacia su triste final. Por momentos, parece la versión real de aquella trágica historia familiar relatada por Lion Feuchtwanger en su novela "Los hermanos Oppermann". El relato comienza en la infancia feliz de los años del Gründerzeit, viéndose pronto sacudida por la Primera Guerra 
Mundial. La guerra afectó a los tres hermanos. En Walter Benjamin se describe su efecto desde el ámbito cultural, que si por un lado le llevó a una crisis de identidad que le acercó al sionismo - guiado por su amigo Gerard Scholem-, por otro le vinculó a las teorías desarrolladas por la Escuela de Frankfurt, a partir de lo cual entró en contacto con destacados pensadores que discurren por las páginas de la obra, como Max Horkheimer, Theodor Adorno o Hannah Arendt. En su hermano Georg, el efecto de la guerra fue político. Combatiente en el frente, conoció la dureza de la guerra y la igualdad de las trincheras. Al regreso a casa se involucró en política, primero militando en el Partido Socialdemócrata Independiente de Alemania y, posteriormente, en el Partido Comunista de Alemania, por el cual llegó a ser diputado. En Dora, se observa el efecto social, tanto por el nuevo lugar ocupado por la mujer en la República de Weimar, como por su preocupación por una reforma que mejorase la calidad de vida de los más desfavorecidos tras la crisis. La vida de los tres hermanos se convierte en un caleidoscopio cuyas lentes encajan perfectamente para dejarnos ver la realidad de aquella época. También los rumbos de sus vidas tras el triunfo nazi nos muestran el diferente porvenir de aquella familia judía. Walter y Dora huyeron a Francia en 1933. En 1940, cuando los nazis invadieron el país galo, Dora consiguió huir a Suiza, donde alcanzaría a ver la derrota de Hitler, pero enferma de cáncer nunca regresó a su país. Walter, por su parte, intentó huir a Estados Unidos pasando por España, pero en la frontera hispana sus sueños se vieron truncados y decidió suicidarse antes de ser entregado a la Gestapo. Mientras, Georg, encarcelado en 1933 tras el incendio del Reichstag, moriría en Mauthausen. Con la muerte de los tres hermanos concluye una primera parte que destaca por su acertada estructura narrativa, su elegante prosa y su riqueza analítica, favorecida por el acceso a numerosa documentación hasta ahora inédita, a la que el autor tuvo acceso gracias a los familiares de Georg, a través de los cuales se adentra en la siguiente parte de la obra.

La segunda parte del libro se centra en la figura de la mujer de Georg Benjamin: Hilde Benjamin (1902-1989). Mediante su recorrido vital, el autor nos relata tanto los duros años bajo el Tercer Reich -tratando de sacar adelante a su hijo Mischa mientras espera la noticia de la muerte de su marido-, como en su actitud ante la posguerra y la nueva Alemania dividida. Sería en la República Democrática de Alemania donde Hilde ocuparía altos cargos: vicepresidenta del Tribunal Supremo y, más tarde, Ministra de Justicia (1953-1967). Es en esta parte donde la riqueza de fuentes es más destacada, algo que contrasta con la menor rigurosidad analítica. Su compasión por las penalidades de la Hilde perseguida por el nacionalsocialismo deriva en una excesiva benevolencia en sus opiniones hacia la que fuera máxima representante de la justicia en la Alemania comunista, relegando a un segundo plano la parte más oscura de quien pronto fue conocida como "Hilde la sanguinaria" o "Guillotina roja". Fue ella la responsable de la represión y depuración de todo aquel considerado sospechoso ante el nuevo partido único: el SED (Partido Socialista Unificado de Alemania). Fue ella la que actuó contra su predecesor en el cargo ministerial, Max Fech- 
ner, desplazado por ser considerado excesivamente "condescendiente" con la sublevación del 17 de junio de 1953. Ella se encargaría de poner fin a esas protestas y de que Fechner, acusado de traición, fuera expulsado del partido y condenado a prisión. Frente a ese terror rojo, Heye prefiere valorar su avanzada legislación social o la depuración emprendida para eliminar cualquier vestigio del pasado nazi, algo que contrapone a una República Federal de Alemania incapaz de afrontar su historia reciente. Además, en su intento por confrontar las diferentes formas en que ambas Alemanias juzgaron al nazismo, Heye acaba por realizar una cierta ruptura discursiva para analizar elementos como la Oficina Federal de Investigación Criminal de la RFA, el Escándalo Spiegel o las dificultades encontradas en su trabajo por el fiscal Fritz Bauer. De este modo, la segunda parte discurre por un terreno pantanoso, donde se entremezcla el análisis condescendiente de Hilde Benjamin, con la reflexión sobre el propio ser de Alemania, con unas consideraciones que restan ritmo a la obra.

Por último, la tercera parte se adentra, aunque de forma más tangencial, en la figura de Mischa Benjamin (1932-2000), hijo de Georg y Hilde. A través de su vida realiza una aproximación crítica a una reunificación que considera movida por un excesivo patriotismo de la RFA que habría olvidado cualquier vestigio positivo que pudiera rescatarse de la legislación social de la RDA. Para ello se vale del desencanto sufrido por un antiguo habitante de Alemania oriental como fue Mischa -también reflejado en su esposa-. Defensor de un comunismo reformado, su apuesta por un "socialismo de rostro humano" Ilevó a que Mischa fuera el principal impulsor de la Plataforma Comunista, sector radical del Partido del Socialismo Democrático (PSD) durante los años 90. Sus iniciativas y decepciones son la guía que conduce al lector hacia el final de la obra, ante una Alemania que se observa en crisis.

En definitiva, el libro de Uwe-Karsten Heye se trata de una publicación original, rica en su prosa, novedosa en ciertas fuentes, pero irregular en su desarrollo; desde un magnífico inicio centrado en la historia de los tres hermanos, a una continuidad donde la obra se aleja de su carácter histórico para aproximarse a un ensayo político que pareciera tratar de retomar aquella vieja Historikerstreit de los años 80. En aquella década se desató una agria polémica respecto a la forma en que la República Federal Alemana debía afrontar su pasado nazi. Ahora, Heye revisa la relación de Alemania con su memoria, evidentemente desencantado con la "quinta Alemania" surgida de la reunificación, a la sombra de una socialdemocracia en crisis y un renacer de la derecha nacionalpopulista encarnada en Alternative für Deutschland. Fue precisamente dicho sentimiento el que le condujo a rescatar la historia de los Benjamin, al considerar, lleno de temor, que "sus vidas se enfrentan al olvido y a una retórica que hoy vuelve a inflarse de nacionalismo".

Adrián Magaldi Fernández

Universidad de Cantabria adrian@magaldi.es 